\title{
Electrochemotherapy of radioresistant head and neck squamous cell carcinoma cells and tumor xenografts
}

\author{
MARTINA NIKSIC ZAKELJ ${ }^{1,2}$, AJDA PREVC ${ }^{1,2}$, SIMONA KRANJC $^{1}$, MAJA CEMAZAR $^{1,3}$, \\ VESNA TODOROVIC $^{1}$, MONIKA SAVARIN $^{1}$, JANEZ SCANCAR $^{4}$, TINA KOSJEK $^{4}$, \\ BLAZ GROSELJ $^{5}$, PRIMOZ STROJAN ${ }^{2,5}$ and GREGOR SERSA ${ }^{1,6}$ \\ ${ }^{1}$ Department of Experimental Oncology, Institute of Oncology Ljubljana; \\ ${ }^{2}$ Faculty of Medicine, University of Ljubljana, SI-1000 Ljubljana; ${ }^{3}$ Faculty of Health Sciences, \\ University of Primorska, SI-6310 Izola; ${ }^{4}$ Department of Environmental Sciences, Jozef Stefan Institute; \\ ${ }^{5}$ Department of Radiation Oncology, Institute of Oncology Ljubljana; \\ ${ }^{6}$ Faculty of Health Sciences, University of Ljubljana, SI-1000 Ljubljana, Slovenia
}

Received August 14, 2018; Accepted December 5, 2018

DOI: 10.3892/or.2019.6960

\begin{abstract}
Electrochemotherapy is an established local ablative method used for the treatment of different tumor types, including tumors of the head and neck area. Clinical studies have demonstrated a lower response rate of tumors that recur in pre-irradiated area. The aim of the present study was to explore the response of experimentally induced radioresistant cells and tumors to electrochemotherapy with cisplatin or bleomycin. The radioresistant cells (FaDu-RR) were established by fractionated irradiation of parental human squamous cell carcinoma cell line, FaDu. We compared the 2 cell lines in response to chemotherapy and electrochemotherapy with cisplatin or bleomycin in vitro and in vivo. Using specific mass spectrometry-based analytical methods we determined the difference in the uptake of chemotherapeutics in tumors after electrochemotherapy. Additionally, we compared the capacity of the cells to repair DNA double-strand breaks (DSB) after exposure to the drugs used in electrochemotherapy with the $\gamma \mathrm{H} 2 \mathrm{AX}$ foci resolution determined by immunofluorescence microscopy. Our results indicate radio- and cisplatin cross-resistance, confirmed with the lower response rate of radioresistant tumors after electrochemotherapy with cisplatin. On the other hand, the sensitivity to electrochemotherapy with
\end{abstract}

Correspondence to: Professor Gregor Sersa, Department of Experimental Oncology, Institute of Oncology Ljubljana, Zaloska Cesta 2, SI-1000 Ljubljana, Slovenia

E-mail: gsersa@onko-i.si

Professor Primoz Strojan, Faculty of Medicine, University of Ljubljana, Zaloska Cesta 2, SI-1000 Ljubljana, Slovenia

E-mail: pstrojan@onko-i.si

Key words: electrochemotherapy, radioresistance, chemoresistance, head and neck cancer, cisplatin, bleomycin, DNA damage, drug uptake bleomycin was similar in both cell lines and tumors. While the uptake of chemotherapeutics after electrochemotherapy was comparable in both tumor models, there was a difference between the cell lines in capacity to repair DNA DSB-the radioresistant cells had a lower level of DSB and faster DNA repair rate after exposure to both, cisplatin or bleomycin. Due to the higher complete response rate after electrochemotherapy with bleomycin than with cisplatin, we conclude that the results favor bleomycin-over cisplatin-based electrochemotherapy for treatment of radioresistant tumors and/or tumors that regrow after radiotherapy.

\section{Introduction}

Electrochemotherapy is an effective local ablative technique that consists of the use of intratumoral or systemic administration of chemotherapeutics (cisplatin or bleomycin) in combination with electroporation. Electroporation is exposure of cells to short, intense electric pulses that enable formation of transient pores in the cell membrane which allow diffusion of chemotherapeutics into the cells, to exert the antitumor effect $(1,2)$.

There are multiple mechanisms of action involved in electrochemotherapy. The primary mechanism is the direct effect on tumor cells, by increased drug accumulation in the cells after electroporation (3). Furthermore, due to the release of tumor antigens after electrochemotherapy and, consequently, the immunogenic cell death, the immune response of the organism is elicited $(4,5)$. There are also indirect effects of electrochemotherapy, the vascular lock and the vascular disruptive effect (6).

Knowledge of the underlying mechanisms of electrochemotherapy has facilitated its translation into clinical practice for the treatment of various cutaneous and subcutaneous tumors. The objective response rate is high, $70-80 \%$ (7-9) and is comparable to other local ablative treatment approaches (10). In the clinic, electrochemotherapy is predominantly used in palliative treatment for cases of recurrent/residual lesions 
after intensive previous treatments using standard modalities. Furthermore, this method can be the first treatment option when surgery or radiotherapy would have caused an aesthetic or functional defect, e.g. in selected tumors of the head and neck area (11-14).

However, recent studies indicate differential effectiveness of electrochemotherapy in different cell types $(15,16)$. Moreover, it has been shown that the effectiveness of electrochemotherapy depends on the tumor histology $(8,17)$, size $(18,19)$ and previous treatment (20). As reported by Campana et al, the pre-treatment with radio- or chemotherapy significantly lowered the response rate of the electrochemotherapy-treated tumors $(20,21)$. One of the possible reasons for this is the endothelial cell dysfunction (increased permeability and apoptosis) caused by irradiation that contributes to post-irradiation inflammation and tissue fibrosis. In cases with the intravenous administration of the drug, the resulted reduction in blood supply can diminish delivery of the drug to tumor cells $(9,22)$. In addition, pre-irradiated recurrent tumors consist of selected, highly resistant malignant cells that survived previous treatment. Intrinsic radioresistance of surviving tumor cells is one of the main obstacles in radiotherapy that affects the curability of the patients and could, together with impaired blood supply, contribute to the lower responsiveness to salvage electrochemotherapy $(23,24)$.

In the head and neck area, many tumors treated by electrochemotherapy have been previously irradiated, which pose several questions: First of all, what is their sensitivity to electrochemotherapy as a potential salvage treatment option; and secondly, whether the differential sensitivity to electrochemotherapy with bleomycin or cisplatin exists.

In order to assess the importance of intrinsic radioresistance in salvage electrochemotherapy for recurrent squamous cell carcinoma of the head and neck, we determined the response rate of a cell line and tumor xenografts in SCID mice of human hypopharyngeal squamous cell carcinoma with induced intrinsic radioresistance to electrochemotherapy with cisplatin or bleomycin. We compared its sensitivity to the parental tumors without the induced radioresistance. Additionally, the uptake of chemotherapeutics in the tumors after electrochemotherapy and capacity of the cells to repair DNA damage after exposure to these drugs were evaluated.

\section{Materials and methods}

Cell lines. In the present study, 2 isogenic cell lines were used: parental $\mathrm{FaDu}$ [human squamous cell carcinoma cell line; obtained from the American Type Culture Collection (ATCC; Manassas, VA, USA)] and the radioresistant subline FaDu-RR, which was established in the laboratory of the Department of Experimental Oncology (Institute of Oncology, Ljubljana, Slovenia) by fractionated irradiation of the FaDu cell line. The cells received 4 cycles of irradiation (30 Gy/cycle; 2 Gy/day; 5 days a week for 3 weeks; the total dose was $120 \mathrm{~Gy}$ ) with the Gulmay 225 X-ray system (Gulmay Medical Ltd., Byfleet, UK) with $0.55 \mathrm{~mm} \mathrm{Cu}$ and $1.8 \mathrm{~mm} \mathrm{Al} \mathrm{filtering,} \mathrm{at} \mathrm{a} \mathrm{dose-rate}$ $1.8 \mathrm{~Gy} / \mathrm{min}$. The radioresistance of the newly established FaDu-RR cells was confirmed with clonogenic assay: The effective dose at $50 \%$ survival $\left(\mathrm{ED}_{50}\right)$ was $1.60 \pm 0.11 \mathrm{~Gy}$ for

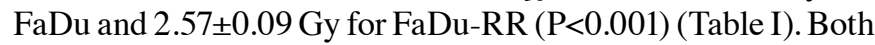

cell lines were grown as a monolayer in Advanced Dulbecco's modified Eagle's medium (DMEM; Gibco; Thermo Fisher Scientific, Inc., Loughborough, UK), supplemented with 5\% fetal bovine serum (FBS; Gibco; Thermo Fisher Scientific, Inc.), $100 \mathrm{U} / \mathrm{ml}$ penicillin (Grünenthal, Aachen, Germany), $50 \mathrm{mg} / \mathrm{ml}$ gentamicin (Krka, Novo Mesto, Slovenia) and 10 mM L-glutamine (GlutaMAX; Gibco; Thermo Fisher Scientific, Inc.). Cells were maintained in a humidified atmosphere at $37^{\circ} \mathrm{C}$ with $5 \% \mathrm{CO}_{2}$.

Animals and tumor models. In total, 120 6- to 8-week old female immunodeficient SCID (C.B-17/IcrHsd-Prkdc ${ }^{\text {scid }}$ ) mice were purchased from Envigo Laboratories (Udine, Italy). They were kept at room temperature $\left(21^{\circ} \mathrm{C}\right)$ with a 12 -h light cycle in a specific pathogen-free environment with food and water ad libitum. The radioresistant and radiosensitive tumor models were induced by subcutaneous injection of $2 \times 10^{6}$ FaDu or FaDu-RR cells in $100 \mu \mathrm{l}$ of $0.9 \%$ sodium chloride (B. Braun Melsungen AG, Melsungen, Germany) solution. To prepare the cell solution, the cells were trypsinized and centrifuged ( $470 \mathrm{x} \mathrm{g}$ for $5 \mathrm{~min}$ ). The cell pellet was then resuspended in $0.9 \%$ sodium chloride, at the concentration of $20 \times 10^{6}$ cells $/ \mathrm{ml}$. To monitor tumor growth, the volume of the tumors was measured using a Vernier caliper, and calculated with the equation for an ellipsoid: $V=(\pi \times a \times b \times c) / 6$ (where $\mathrm{a}, \mathrm{b}$ and $\mathrm{c}$ are 3 perpendicular diameters of the tumor). When the tumors reached $6 \mathrm{~mm}$ in the longest diameter $\left(\sim 40 \mathrm{~mm}^{3}\right)$, the mice were divided randomly into experimental groups, consisting of 5-7 mice, and the treatment started according to the protocol. The experiments were approved by the Ministry of Agriculture, Forestry and Food of the Republic of Slovenia (permit no. U34401-1/2015/16), and were in compliance with the standards required by the UKCCCR guidelines and the EU directive.

Histology. The radioresistant and radiosensitive tumors (3/group) were induced as described above. When the tumors reached $\sim 100 \mathrm{~mm}^{3}$ in size, they were excised, separated from the skin, fixed in a zinc fixative [BD Pharmingen ${ }^{\mathrm{TM}} 10 \mathrm{X}$ Zinc Fixative (Formalin free); BD Biosciences, San Diego, CA, USA] and embedded in paraffin. From each paraffin block $2-\mu$ m-thick sections were cut and stained with Masson trichrome, as well as immunohistochemically (IHC) to determine proliferation (Ki-67; cat. no. RM9106S1; Thermo Fisher Scientific, Inc., Waltham, MA, USA), hypoxia (HIF-1 $\alpha$; dilution 1:1,000; cat. no. ab2185; Abcam, Cambridge, UK) and the number of tumor blood vessels (anti-CD31 antibody; dilution 1:1,500; cat. no. ab28364; Abcam). From the slides, 5 random parts of each tumor were selected and captured with a DP72 CCD camera (Olympus Corp., Tokyo, Japan) connected to an Olympus BX-51 fluorescence microscope (Olympus Corp.). Images were quantitatively evaluated by 3 independent researchers, as previously described (25).

Exposure to chemotherapeutics in vitro. Cells were plated on Petri dishes (VWR International GmbH, Wien, Austria). When the cells attached, various concentrations of cisplatin (ranging from 1.67 to $8.33 \mu \mathrm{M}$ ) or bleomycin (from 2.5 to $20 \mu \mathrm{M})$ suspensions were prepared out of a stock cisplatin $(1 \mathrm{mg} / \mathrm{ml}$; Cisplatina Kabi; Fresenius Kabi AG, 
Table I. Radiosensitivity of FaDu and FaDu-RR cell lines.

\begin{tabular}{lcccc}
\hline Cell line & $\mathrm{ED}_{50} \pm \mathrm{SEM}$ & $\mathrm{DMF}\left(\mathrm{ED}_{50}\right)$ & $\mathrm{ED}_{90} \pm \mathrm{SEM}$ & $\mathrm{DMF}_{\left(\mathrm{ED}_{90}\right)}$ \\
\hline FaDu & $1.60 \pm 0.11$ & 1 & $4.16 \pm 0.13$ & 1 \\
FaDu-RR & $2.57 \pm 0.09^{\mathrm{a}}$ & 1.60 & $5.35 \pm 0.13^{\mathrm{a}}$ & 1.29 \\
\hline
\end{tabular}

Comparison between parental $(\mathrm{FaDu})$ and radioresistant $(\mathrm{FaDu}-\mathrm{RR})$ cell lines in sensitivity to irradiation. The $\mathrm{ED}_{50}$ and $\mathrm{ED}_{90}$ values are represented as the arithmetic mean $(\mathrm{AM}) \pm$ standard error of the mean (SEM) from at least 3 independent experiments, performed in triplicates. $\mathrm{DMF}$, dose-modifying factor; $\mathrm{ED}_{50}$, effective dose killing $50 \%$ of the cells; $\mathrm{ED}_{90}$, effective dose killing $90 \%$ of the cells. ${ }^{\mathrm{a}} \mathrm{P}<0.05$, significantly different from the parental $\mathrm{FaDu}$ cells.

Bad Homburg, Germany) or bleomycin ( $3 \mathrm{mg} / \mathrm{ml}$; Heinrich Marck Nachf GmbH, Illertissen, Germany) suspensions, respectively, and added to the culture medium with the cells. After $2 \mathrm{~h}$, the medium containing the chemotherapeutics was replaced with fresh medium. The cell survival was determined by clonogenic assay, where the plating efficiency (ratio between the number of colonies and the number of plated cells) and surviving fraction (ratio between the plating efficiency of the treated groups and control group) of the cells were calculated.

Electrochemotherapy in vitro. In this experiment, $90 \mu \mathrm{l}$ of cell suspension $\left[2.2 \times 10^{7}\right.$ cells $/ \mathrm{ml}$ in electroporation buffer (125 mM sucrose, $10 \mathrm{mM} \mathrm{K} \mathrm{HPO}_{4}, 2.5 \mathrm{mM} \mathrm{KH}_{2} \mathrm{PO}_{4}$ and $\left.2 \mathrm{mM} \mathrm{MgCl}_{2} \times 6 \mathrm{H}_{2} 0\right)$ ] (26) was mixed with $10 \mu \mathrm{l}$ of culture medium, containing increasing concentrations of cisplatin (from 1.67 to $33.32 \mu \mathrm{M}$ ) or bleomycin (from $10^{-5}$ to $1 \mu \mathrm{M}$ ). One-half of the mixture was exposed to electric pulses and the other half served as control for treatment with the chemotherapeutics alone. After that, the cells were incubated for $5 \mathrm{~min}$ at room temperature in ultra-low attachment plates (Costar $^{\circledR}$ 24-Well Plate, Ultra-Low Attachment Surface; Corning Inc., Corning, NY, USA), then diluted in the cell culture medium and plated on Petri dishes for the clonogenic assay. The parameters of electrical pulses were 8 square wave electric pulses, amplitude over distance ratio of $1,300 \mathrm{~V} / \mathrm{cm}$ and pulse duration of $100 \mu \mathrm{sec}$ at a frequency of $1 \mathrm{~Hz}$. The pulses were delivered by electroporator GT-01 (Faculty of Electrical Engineering, University of Ljubljana, Ljubljana, Slovenia) using 2 parallel stainless steel plate electrodes with $2 \mathrm{~mm}$ of inner distance.

As a part of this experiment, the electropermeabilization of these 2 cell lines was determined, measuring the propidium iodide (PI) uptake immediately after electroporation (using electric field intensities from 400 to 1,600 V/cm). The increase in uptake of PI after electroporation was used as an indicator of electropermeability of cells. The measurement of median fluorescence and percentage of PI-positive cells was carried out with FACSCanto II flow cytometer (BD Biosciences) as described by Prevc et al (27).

Electrochemotherapy in vivo. The mice bearing either radioresistant or radiosensitive tumors were divided into the following experimental groups (5-7 mice/group): the control (received no therapy), the electroporation-only, the chemotherapy and the electrochemotherapy group. The mice in the chemotherapy group received cisplatin- or bleomycin-based chemotherapy. They were injected with $4 \mathrm{mg} / \mathrm{kg}$ cisplatin (concentration 1,142.8 $\mu \mathrm{g} / \mathrm{ml}$ ) or $5 \mathrm{mg} / \mathrm{kg}$ bleomycin (concentration $1,492.5 \mu \mathrm{g} / \mathrm{ml}$ ), dissolved in $0.9 \%$ sodium chloride, into the retro-orbital sinus. Selection of the chemotherapeutic dosage for electrochemotherapy was based on previous studies $(28,29)$ and was in the range where complete responses of different tumor models were expected. For electrochemotherapy-treated tumors, electric pulses ( 8 electrical pulses of $100 \mu \mathrm{sec}$ duration at $1 \mathrm{~Hz}$, the electric field intensity was $1,300 \mathrm{~V} / \mathrm{cm}$ ) were applied $3 \mathrm{~min}$ after the mice were i.v. injected with cisplatin or bleomycin. The electric pulses were delivered by ELECTRO Cell B10 electric pulse generator (Leroy Biotech, Saint-Orens-de-Gameville, France) using 2 stainless steel plate electrodes with 6-mm inner distance. When the tumors reached $250 \mathrm{~mm}^{3}$ in size, the mice were sacrificed with cervical dislocation that followed anesthesia with 3\% isoflurane. Survival (Kaplan-Meier) curves were drawn. Growth delay (GD) was calculated as the difference in tumor doubling time (DT) of the treated groups and DT of the corresponding control group. Due to the difference in the growth rate of control tumors ( $\mathrm{FaDu}$ vs. FaDu-RR), also the normalized GD (nGD) was calculated for each treated group (30).

Platinum determination in vitro and in vivo. The uptake of cisplatin was evaluated after chemo- and electrochemotherapy, both in vitro and in vivo. To determine and compare the cisplatin uptake in vitro, the cells were first treated with chemotherapy (exposure to $5 \mu \mathrm{M}$ cisplatin for $5 \mathrm{~min}$, or $2 \mathrm{~h}$; $\mathrm{n}=3$ ) or with electrochemotherapy (using the same cisplatin concentration, the exposure time was $5 \mathrm{~min} ; \mathrm{n}=3$ ). Then, the cells were centrifuged at $470 \mathrm{x}$ g for $5 \mathrm{~min}$ and the cell pellet was stored at $-20^{\circ} \mathrm{C}$ until further analysis.

The protocol for the in vivo measurement was adapted from our previous study, described by Kranjc et al (31). Briefly, the mice were first treated with chemotherapy or electrochemotherapy with cisplatin (6 mice/group). One hour after the treatment (32), the blood of the treated mice was collected with a glass capillary from the intra-orbital sinus and centrifuged at $1,811 \mathrm{x} \mathrm{g}$ for $10 \mathrm{~min}$. Then, the serum was collected and stored at $-20^{\circ} \mathrm{C}$. After the blood collection, the mice were sacrificed with cervical dislocation that followed anesthesia with $3 \%$ isoflurane; the tumors were excised and separated from the overlying skin, weighed and stored at $-20^{\circ} \mathrm{C}$ until further analysis. 
All the collected samples were first digested in 1:1 mixture of $65 \%$ nitric acid (Merck KGaA, Darmstadt, Germany) and $30 \%$ hydrogen peroxide (Merck $\mathrm{KGaA}$ ) at $90^{\circ} \mathrm{C}$ for $48 \mathrm{~h}$. Before analyses, digested samples were diluted with Milli-Q water (Direct-Q 5 Ultrapure water system; EMD Millipore, Watertown, MA, USA). Platinum content was determined by inductively coupled plasma mass spectrometry (7,700x ICP-MS; Agilent Technologies Japan Ltd., Tokyo, Japan) by monitoring the ${ }^{195} \mathrm{Pt}$ and ${ }^{194} \mathrm{Pt}$ isotopes $(33,34)$. The measured platinum content in samples (given in ng) obtained from tumors was then divided by the mass of the tumor $(\mathrm{g})$; the serum samples were divided by the volume of isolated serum (ml); the samples from the in vitro experiment were normalized to number of cells in the pellet (ng/10 6 cells).

Bleomycin determination in vivo. The samples for bleomycin determination were obtained in the same way as for platinum determination after in vivo chemo- and electrochemotherapy, using 6 mice/group. For analysis, the tumor samples were ground to fine powder under liquid nitrogen, sonicated, centrifuged and filtered. After the purification with solid phase extraction the bleomycin concentration was determined by liquid chromatography coupled to tandem mass spectrometry (LC-MS/MS) on Nexera ultra high performance LC (Shimadzu Corp., Kyoto, Japan) coupled to QTRAP ${ }^{\circledR}$ 4500 MS/MS system (AB Sciex Germany GmbH, Darmstadt, Germany) (35). The measured bleomycin concentration in each sample was then normalized to the mass of the tumor or to the volume of the isolated serum, as described above.

$\gamma H 2 A X$ immunofluorescent staining. For determination of DNA double-strand breaks (DSB) after exposure to cisplatin or bleomycin, the cells were first plated on coverslips in 6-well plates and then exposed to $3.33 \mu \mathrm{M}$ of cisplatin or $5 \mu \mathrm{M}$ of bleomycin in cell medium for $2 \mathrm{~h}$. At different time-points after the exposure, the cells were fixed in a mixture of 4\% paraformaldehyde [Thermo Fisher (Kendel) $\mathrm{GmbH}$, Karlsruhe, Germany] and 0.1\% Triton X-114 (Sigma-Aldrich; Merck KGaA), and then permeabilized in $0.5 \%$ Triton X-114 and after that blocked in 5\% bovine serum albumin (BSA; Sigma-Aldrich; Merck KGaA). Cells were then incubated overnight at $4^{\circ} \mathrm{C}$ in mouse monoclonal anti- $\gamma$ H2A.X (phospho S 139) antibody [9F3] (cat. no. ab26350; Abcam, Cambridge, MA, USA) at dilution 1:3,000 in a 5\% BSA and $0.1 \%$ Triton X-114 mixture. The cells were then washed thoroughly with phosphate-buffered saline (PBS) and incubated in secondary donkey anti-mouse IgG H\&L (Alexa Fluor 488) antibody (cat. no. ab150105; Abcam) at dilution 1:2,000 in $0.1 \%$ Triton X-114 for $1 \mathrm{~h}$ at room temperature. The cells were then washed with PBS and distilled water, and the coverslips were mounted on microscope slides with Fluoroshield with DAPI (Sigma-Aldrich; Merck KGaA) for nuclei counterstaining, dried and viewed under the Olympus BX-51 fluorescence microscope (Olympus Corp.) equipped with a camera DP72 (Olympus Corp). Filter U-MWIB (Olympus Corp.) was used for $\gamma \mathrm{H} 2 \mathrm{AX}$ foci and U-MWU2 (Olympus Corp.) was used for nuclei counterstaining at 100 -fold magnification. The number of $\gamma \mathrm{H} 2 \mathrm{AX}$ foci/nuclei was evaluated by image analysis using Fiji software (ImageJ image processing program; National Institutes of Health, Bethesda, MD, USA) (36). For the analysis, $\gamma \mathrm{H} 2 \mathrm{AX}$ foci were determined in control groups as well (i.e. cells received no treatment) in both cell lines to assess the baseline number of foci/nucleus. In both control groups, $>90 \%$ of nuclei had 3 or fewer foci; therefore, in the analysis of the treated cells, nuclei with $>3$ foci were considered as $\gamma \mathrm{H} 2 \mathrm{AX}$-positive.

Statistical analysis. Statistical analysis and graphical representation of the results were performed by SigmaPlot Software (version 13; Systat Software, Hounslow, UK). All data were tested for normal distribution using Shapiro-Wilk test and the arithmetic mean (AM) and standard error of the mean (SEM) were calculated. Statistical difference between the experimental groups (chemo- and electrochemotherapy in vitro, electropermeabilization, platinum and bleomycin uptake) was determined with a t-test and one-way analysis of variance (one-way ANOVA) followed by a Holm-Sidak test. In the $\gamma \mathrm{H} 2 \mathrm{AX}$ test, the data are presented as the median and quartiles and the Mann-Whitney rank sum test was used to assess the statistically significant differences. For the statistical analysis of the in vivo growth delay data, the growth delay of tumors in experimental groups was normalized to the doubling time of tumors in the control group of each model due to the difference between growth rates of the 2 models. For the survival of mice, Kaplan-Meier survival analysis was performed. The difference between experimental groups was considered significant if the P-value was $<0.05$.

\section{Results}

Characterization of the cell lines. The 2 cell lines differed in growth characteristics; the doubling time in FaDu cells was $25 \pm 1.2 \mathrm{~h}$, while in FaDu-RR cells, the doubling time was $34.6 \pm 2.9 \mathrm{~h}$. The FaDu cell line and its radioresistant subline FaDu-RR differed in sensitivity to a 2 -h exposure to cisplatin. The radioresistant cell line FaDu-RR was more resistant to cisplatin compared to the parental FaDu cell line $\left(\mathrm{IC}_{50}\right.$ for $\mathrm{FaDu}$ was $2.55 \pm 0.56$ and $4.36 \pm 0.61 \mu \mathrm{M}$ for FaDu-RR; $\mathrm{P}<0.001$ ) (Fig. 1A). However, the 2 cell lines were equally sensitive to a 2-h exposure to bleomycin $\left(\mathrm{IC}_{50}\right.$ for $\mathrm{FaDu}$ was 5.93 \pm 0.34 and 6.63 $\pm 0.47 \mu \mathrm{M}$ for FaDu-RR; $\mathrm{P}=0.540$ ) (Fig. 1B).

While the exposure of the cells to electric pulses significantly increased the response of the cell lines to both chemotherapeutics $(\mathrm{P}<0.001)$, there was no difference between the cell lines in sensitivity to electrochemotherapy with cisplatin or with bleomycin (Fig. 1C and D). Furthermore, the cells did not differ in membrane electropermeabilization, which was measured with the PI uptake. The percentage of PI-positive cells at $1,300 \mathrm{~V} / \mathrm{cm}$ (i.e. electric field intensity that is used in electrochemotherapy) was $95 \%$ in both cell lines (Fig. 1E and F), indicating that the resistance of FaDu-RR cells to cisplatin may be due to the impaired influx of cisplatin. By cell electroporation, however, this restriction was overcome and both cell lines were equally sensitive to electrochemotherapy with cisplatin.

Characterization of the tumor models. Characteristics of the radiosensitive and radioresistant tumors differed significantly with respect to growth rate and histological properties. The radioresistant tumors grew slower (DT of control groups 
A

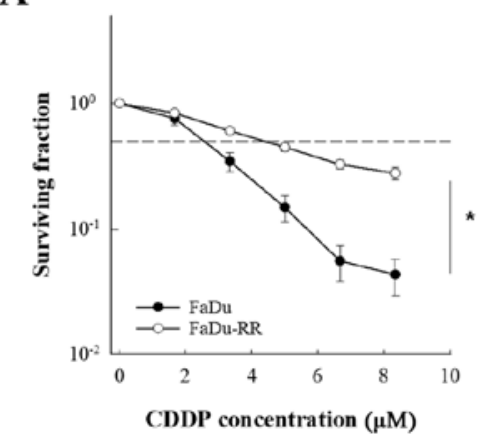

B

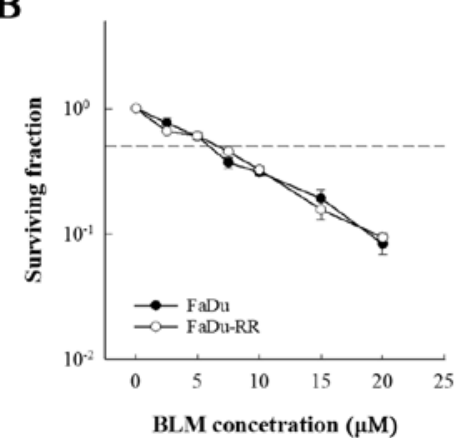

$\mathrm{C}$

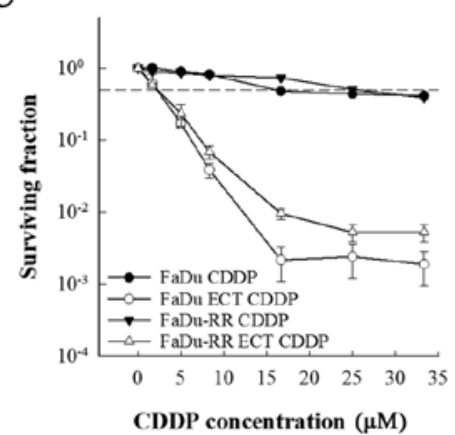

D

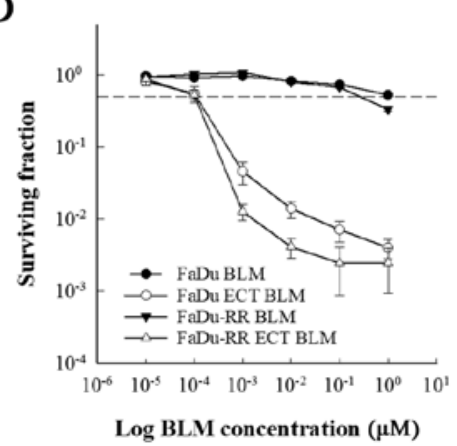

E

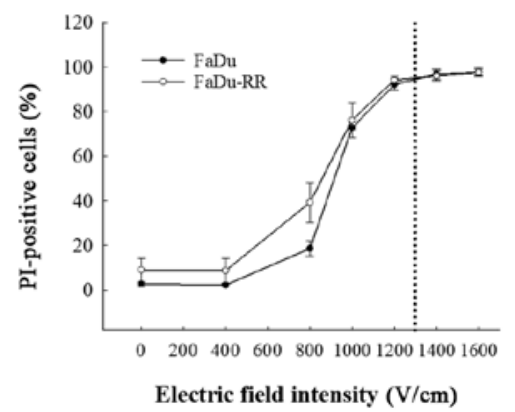

$\mathrm{F}$

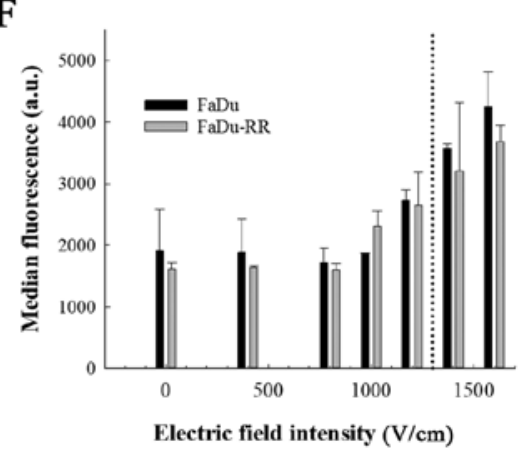

Figure 1. In vitro comparison of the sensitivity to chemotherapy and electrochemotherapy and electropermeability between the parental cell line and radioresistant subline. Survival curves of radiosensitive (FaDu) and radioresistant (FaDu-RR) cells after (A) 2-h exposure to cisplatin or (B) bleomycin and after electrochemotherapy with (C) cisplatin or (D) bleomycin. (E and F) Electropermeabilization of the cell membranes after exposure to electric pulses. The data for the electrochemotherapy are normalized to the corresponding control group without the chemotherapeutic agent (with or without pulse application). CDDP, cisplatin; BLM, bleomycin; ECT, electrochemotherapy; PI, propidium iodide. * $\mathrm{P}<0.001$. Data are represented as arithmetic mean (AM) and standard error of the mean $(\mathrm{SEM})(\mathrm{AM} \pm \mathrm{SEM})$ of at least 3 independent experiments performed in triplicates. Dashed lines represent inhibitory concentration of the chemotherapeutic killing $50 \%$ of the cells $\left(\mathrm{IC}_{50}\right)$. Dotted lines in $\mathrm{E}$ and $\mathrm{F}$ represent electric field intensity of $1,300 \mathrm{~V} / \mathrm{cm}$.

was $1.8 \pm 0.2$ days for $\mathrm{FaDu}$ and $2.6 \pm 0.4$ days for FaDu-RR; $\mathrm{P}=0.067$ ), which was reflected in the lower proliferation rate of radioresistant tumors: The percentage of the proliferative cells, obtained with IHC staining for the proliferative marker Ki-67, was $83.1 \pm 1.3 \%$ in FaDu and 53.6 $\pm 3.3 \%$ in FaDu-RR $(\mathrm{P}<0.001)$. Furthermore, radioresistant tumors were less vascularized, with a lower average number of blood vessels/field (60-fold magnification), obtained with IHC staining for endothelial cell marker CD31, compared to radiosensitive tumors (12.6 \pm 1.0 in FaDu vs. $5.2 \pm 0.5$ in FaDu-RR; $\mathrm{P}<0.001)$. The difference in tumor structure was also noticeable: in $\mathrm{FaDu}$ tumors the connective tissue was evenly distributed between the cells while in FaDu-RR tumors, it was less organized in individual bundles. Despite the difference, the percentage of connective tissue was similar in both tumor models $(17.3 \pm 1.1$ in FaDu vs. $20.3 \pm 1.0 \%$ in FaDu-RR; $\mathrm{P}=0.094)$. Furthermore, the tumors did not differ in the percentage of hypoxic cells $(5.7 \pm 0.6$ in FaDu vs. $4.5 \pm 0.6 \%$ in FaDu-RR; $\mathrm{P}=0.119$ ), most likely due to the small size of the tumors at the time of the histological analyses ( 100-150 $\left.\mathrm{mm}^{3}\right)$ (Fig. 2).

Electrochemotherapy in vivo. Treatment of FaDu or FaDu-RR tumors with cisplatin or bleomycin alone had no effect on their growth, due to relatively low doses of the chemotherapeutics that were used. However, the FaDu-RR tumors were more resistant to electrochemotherapy with cisplatin, compared to FaDu tumors: FaDu-RR tumors had shorter nGD (10.3 \pm 0.9 in
FaDu-RR, 18.6 \pm 3.2 in $\mathrm{FaDu} ; \mathrm{P}=0.026)$ and had no complete responses (CR), while in $\mathrm{FaDu}$ tumors there was $16.7 \%$ of $\mathrm{CR}(\mathrm{P}=0.015)$ (Fig. 3A).

After electrochemotherapy of radiosensitive FaDu and radioresistant FaDu-RR tumors with bleomycin, there was no difference in the survival curves $(\mathrm{P}=0.900)$, with $40 \%$ of $\mathrm{CR}$ and comparable nGD $(30.9 \pm 5.8$ in FaDu vs. $27.9 \pm 2.1$ in FaDu-RR tumors; $\mathrm{P}=0.787$ ) obtained in the 2 groups (Fig. 3B).

Platinum and bleomycin accumulation. The content of both chemotherapeutics in the tumors and serum was measured $1 \mathrm{~h}$ after the treatment with chemotherapy and electrochemotherapy. While there was no difference in platinum or bleomycin accumulation in the serum of mice with $\mathrm{FaDu}$ or FaDu-RR tumors (Fig. 4A and B), the tumor uptake of cisplatin was lower in the radioresistant tumors compared to the radiosensitive ones $(1.05 \pm 0.02 \mu \mathrm{g} / \mathrm{g}$ in $\mathrm{FaDu}$ vs. $0.90 \pm 0.04 \mu \mathrm{g} / \mathrm{g}$ in FaDu-RR; $\mathrm{P}=0.010)$. Nevertheless, after the electrochemotherapy, there was no difference in the uptake of chemotherapeutics between the 2 tumor models: The measured bleomycin concentration in tumors was $0.47 \pm 0.06 \mu \mathrm{g} / \mathrm{g}$ in FaDu and $0.42 \pm 0.06 \mu \mathrm{g} / \mathrm{g}$ in FaDu-RR $(\mathrm{P}=0.602)$; the platinum concentration was $2.07 \pm 0.23 \mu \mathrm{g} / \mathrm{g}$ in $\mathrm{FaDu}$ and $2.41 \pm 0.25 \mu \mathrm{g} / \mathrm{g}$ in FaDu-RR (Fig. 4C and D). Tumor uptake of bleomycin was comparable between $\mathrm{FaDu}$ and FaDu-RR tumors, either in case of drug administration only or after adding electric 


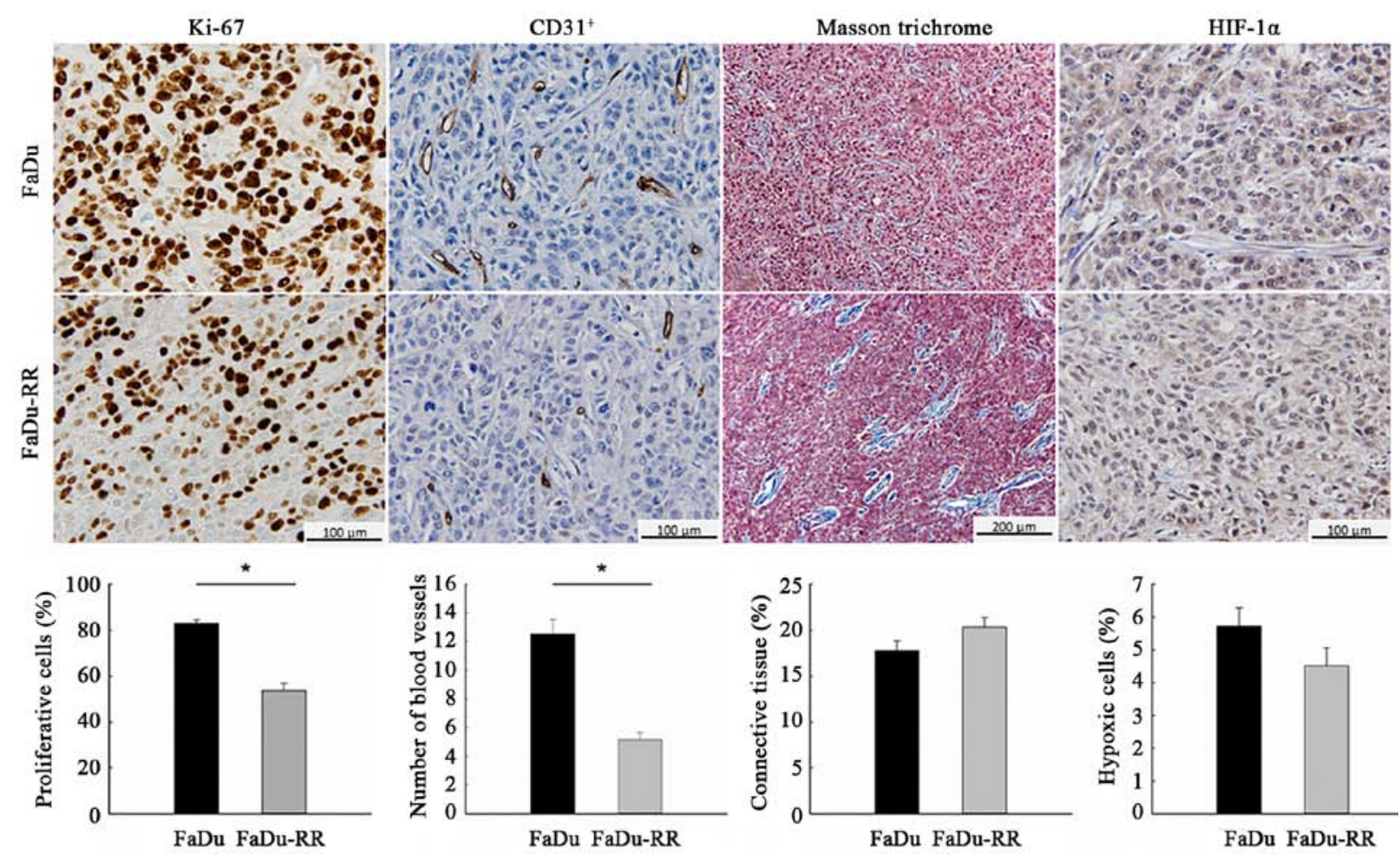

Figure 2. Histological differences between radioresistant and radiosensitive tumors. The IHC stained tumor slides with the corresponding graphs, comparing radiosensitive $(\mathrm{FaDu})$ and radioresistant $(\mathrm{FaDu}-\mathrm{RR})$ tumors. Data are represented as arithmetic mean $(\mathrm{AM})$ and standard error of the mean $(\mathrm{SEM})(\mathrm{AM} \pm \mathrm{SEM})$; $\mathrm{n}=3$ mice; Ki-67, proliferation marker; CD 31 ${ }^{+}$, marker for endothelial cells; HIF-1 $\alpha$, hypoxia-inducible factor $1-\alpha ;{ }^{*} \mathrm{P}<0.05$ between FaDu and FaDu-RR tumors.

A

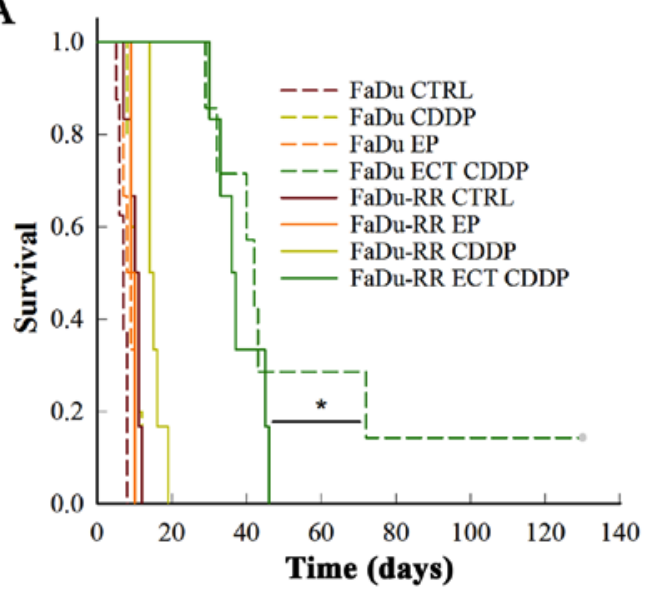

B

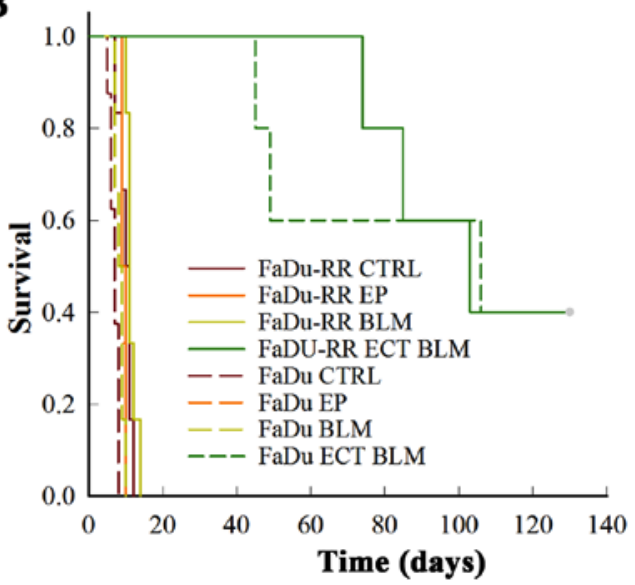

Figure 3. Antitumor effectiveness of electrochemotherapy with cisplatin (A) or bleomycin (B). Kaplan-Meier survival curves of the mice with radiosensitive $(\mathrm{FaDu})$ or radioresistant $(\mathrm{FaDu}-\mathrm{RR})$ tumors after treatment with i.v. injection of cisplatin (CDDP) or bleomycin (BLM) alone, or in combination with electrical pulses-electrochemotherapy (ECT), and after treatment with electrical pulses alone (EP). ${ }^{*} \mathrm{P}<0.05$ between FaDu and FaDu-RR tumor model after ECT with CDDP, $\mathrm{n}=5-7$ mice. CTRL, control group.

pulses. The potentiation of the drug content in tumors after application of the electrical pulses was higher after electrochemotherapy with bleomycin (7.6-fold in $\mathrm{FaDu}$ and 4.7-fold in FaDu-RR) than with cisplatin (2-fold in FaDu and 2.7-fold in FaDu-RR).

The in vitro experiment (Fig. 4E) showed no difference between the cell lines in regards to platinum accumulation after a 5 -min exposure to cisplatin $\left(0.69 \pm 0.11 \mathrm{ng} / 10^{6}\right.$ cells in $\mathrm{FaDu}$ vs. $1.17 \pm 0.52 \mathrm{ng} / 10^{6}$ cells in $\mathrm{FaDu}-\mathrm{RR}$; $\mathrm{P}=0.210$ ) or after electrochemotherapy $\left(1.67 \pm 0.50 \mathrm{ng} / 10^{6}\right.$ cells in $\mathrm{FaDu}$ vs. $1.47 \pm 0.26 \mathrm{ng} / 10^{6}$ cells in FaDu-RR; $\mathrm{P}=0.734$ ).
With the additional experiment, where the exposure time to cisplatin alone was prolonged to $2 \mathrm{~h}$ (Fig. $4 \mathrm{~F}$ ), the in vivo results were confirmed, demonstrating lower platinum accumulation in FaDu-RR cells ( $2.16 \pm 0.02$ ng $/ 10^{6}$ cells in $\mathrm{FaDu}$ vs. $1.33 \pm 0.16 \mathrm{ng} / 10^{6}$ cells in FaDu-RR; $\mathrm{P}=0.006$ ).

The bleomycin uptake in vitro was not performed due to insufficient sensitivity of the analytical method for determination of bleomycin in the cells.

DNA double-strand breaks: Level and repair rate. The $\gamma$-H2AX foci were determined at several time-points (i.e., 


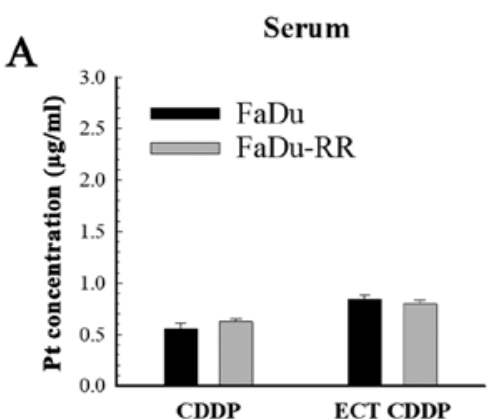

B

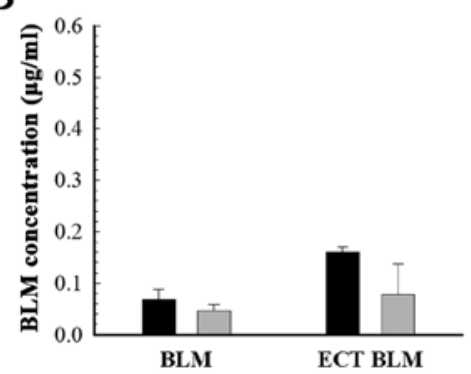

$\mathrm{C}$

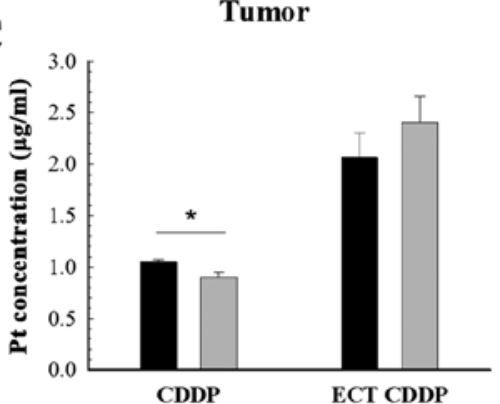

$\mathrm{D}$

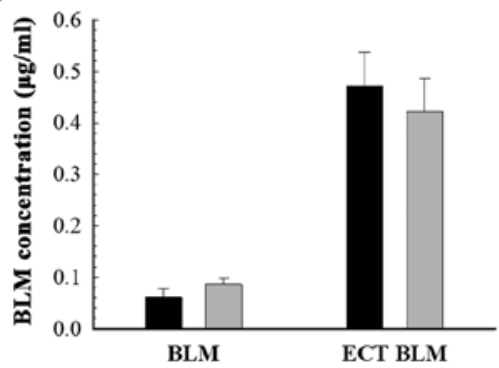

Cells $^{\star *}$

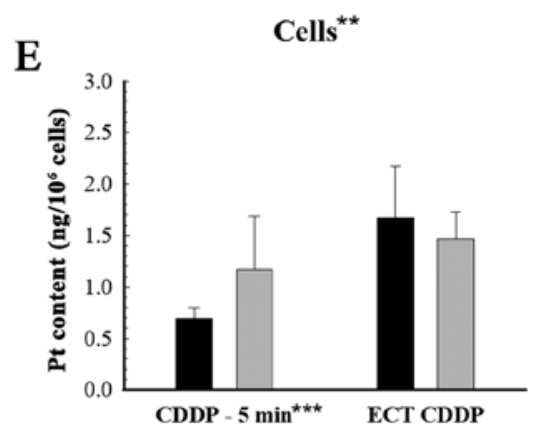

F

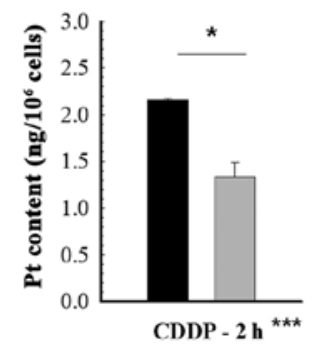

Figure 4. Platinum and bleomycin accumulation in serum, tumors and cells after chemotherapy and electrochemotherapy with cisplatin or bleomycin. Platinum and bleomycin content in serum (A and B) and tumors (C and D) after i.v. injection of cisplatin (CDDP) or bleomycin (BLM) alone, or in combination with electric pulses $(\mathrm{ECT})$ in radiosensitive $(\mathrm{FaDu})$ and radioresistant $(\mathrm{FaDu}-\mathrm{RR})$ tumors. (E and $\mathrm{F})$ The uptake of cisplatin in vitro. Data are represented as arithmetic mean (AM) and standard error of the mean (SEM) (AM \pm SEM). (A-D) $n=6$; (E and F) $n=3 .{ }^{*} \mathrm{P}<0.05$ between FaDu and FaDu-RR tumors. ** Data shown for cisplatin only; ${ }^{* * *}$ Exposure to $5 \mu \mathrm{M}$ cisplatin for $5 \mathrm{~min}$, or $2 \mathrm{~h}$.

6-48 $\mathrm{h}$ after exposure to cisplatin and 1-24 $\mathrm{h}$ after exposure to bleomycin) with intention to assess the differences in the repair rate of DNA DSBs. The efficiency of the repair was evaluated at the last time-point (48 $\mathrm{h}$ after cisplatin and $24 \mathrm{~h}$ after bleomycin) as the residual foci indicate the capacity of cells to repair the DNA damage and consequently cell survival (37). Our results suggest that the radioresistant cells repaired DSBs faster and more effectively than the parental cells, regardless of the drug that the cells were exposed to. The percentage of $\gamma \mathrm{H} 2 \mathrm{AX}$-positive nuclei at the last time point after exposure to cisplatin or to bleomycin was significantly lower in FaDu-RR cells (after cisplatin: $38.2 \pm 4.6$ in $\mathrm{FaDu}$ vs. $14.1 \pm 0.9 \%$ in FaDu-RR; $\mathrm{P}=0.007$; after bleomycin: $42.5 \pm 8.3$ in FaDu vs. $12.0 \pm 5.2 \%$ in FaDu-RR; $\mathrm{P}=0.036$ ). Furthermore, the FaDu cells exhibited a higher level of DNA DSBs after exposure to chemotherapeutics, which was demonstrated by a higher median number of foci/nucleus in FaDu cells; the highest level of foci was detected $18 \mathrm{~h}$ after exposure to cisplatin (4 foci/nucleus in $\mathrm{FaDu}$ vs. 3 foci/nucleus in FaDu-RR; $\mathrm{P}=0.128$ ) and $2 \mathrm{~h}$ after exposure to bleomycin (12 foci/nucleus in $\mathrm{FaDu}$ vs. 3 foci/nucleus in FaDu-RR; $\mathrm{P}<0.001$ ) (Fig. 5C and D).

\section{Discussion}

In the present study, we compared the in vitro and in vivo response of 2 isogenic head and neck cell lines with different radiosensitivity to electrochemotherapy with cisplatin or bleomycin to explore the influence of intrinsic radiosensitivity to the outcome of electrochemotherapy. In addition, the difference in the DNA-damage response after exposure to cisplatin or bleomycin, as well as the difference in the uptake of these drugs, were explored.
The in vivo results indicate that radioresistant tumors were also resistant to electrochemotherapy with cisplatin, but were equally sensitive to electrochemotherapy with bleomycin. Due to the higher complete response rate after electrochemotherapy with bleomycin than with cisplatin, the results favor bleomycin over cisplatin-based electrochemotherapy for treatment of radioresistant tumors and/or tumors that regrow after radiotherapy.

To explore the role of intrinsic radioresistance of tumor cells in the response to treatment with electrochemotherapy, we selected the model where the radioresistant cells were derived from the parental cells, and selected pharyngeal squamous cell carcinoma, since many head and neck tumors that are treated by electrochemotherapy, are pre-irradiated tumors $(20,38)$. We established an isogenic radioresistant cell subline from the head and neck FaDu cell line through repeated exposure to irradiation. The so-called 'isogenic models of radioresistance' (39) have already been widely used to study molecular response to irradiation in numerous human cancer cell lines where the selection of a radioresistant subline was achieved through repeated exposure of parental cells to fractionated irradiation of variable overall total dose and treatment time (40-44). Several differences have been observed in radioresistant sublines compared to their parental cell lines, including higher cellular levels of glutathione (45), reduced induction of apoptosis (46) and increased ability to repair DNA damage (47). Furthermore, cross-resistance with DNA-damaging agents, especially with cisplatin, was observed $(42,46,48)$. Addiitonally, in the clinic, observations indicate that development of radioresistance correlates with the chemoresistance of the tumors and vice versa. Moreover, the tumor response to induction chemotherapy is considered 
A

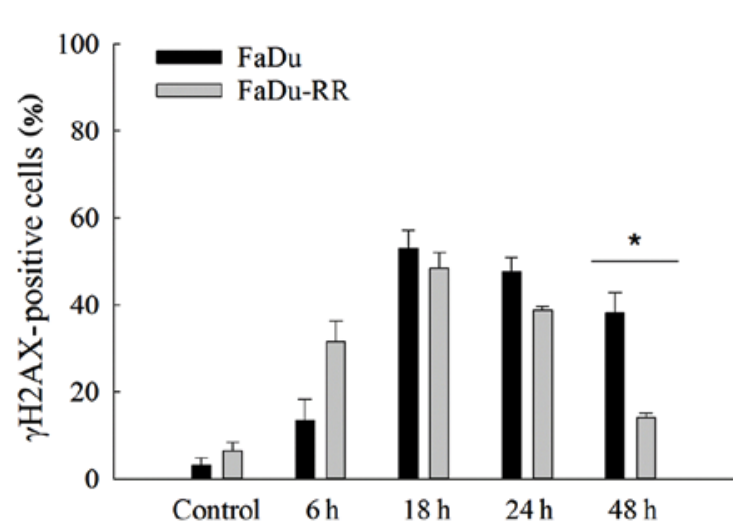

$\mathrm{C}$

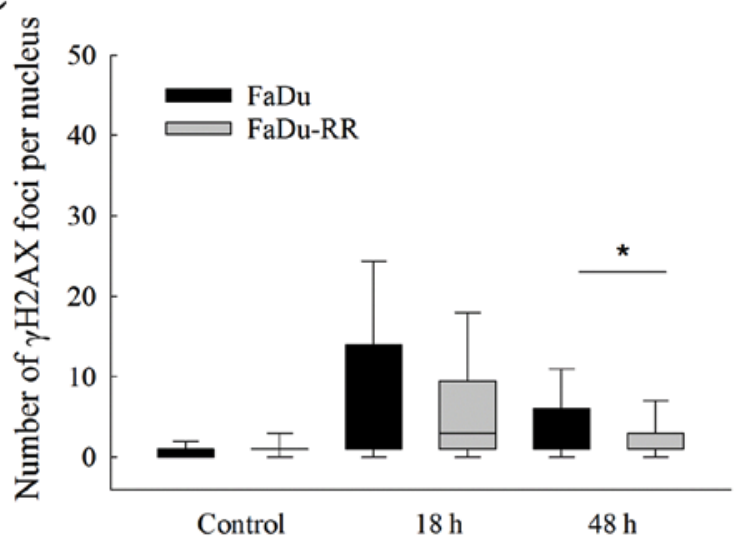

$\mathrm{E}$

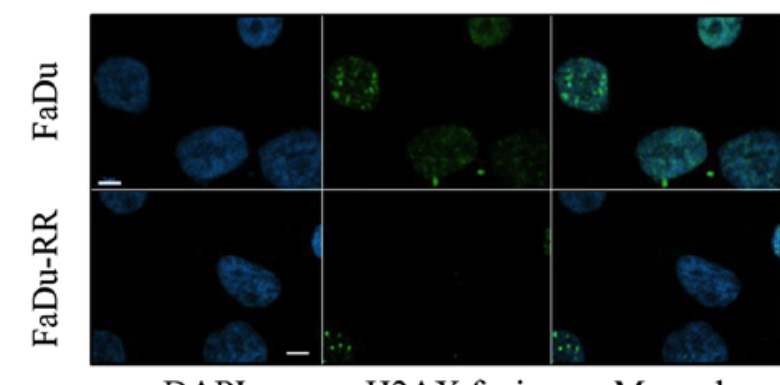

B

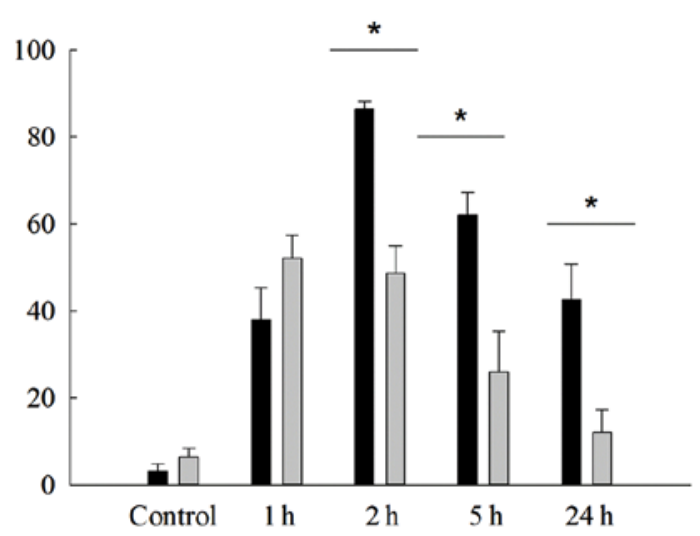

D
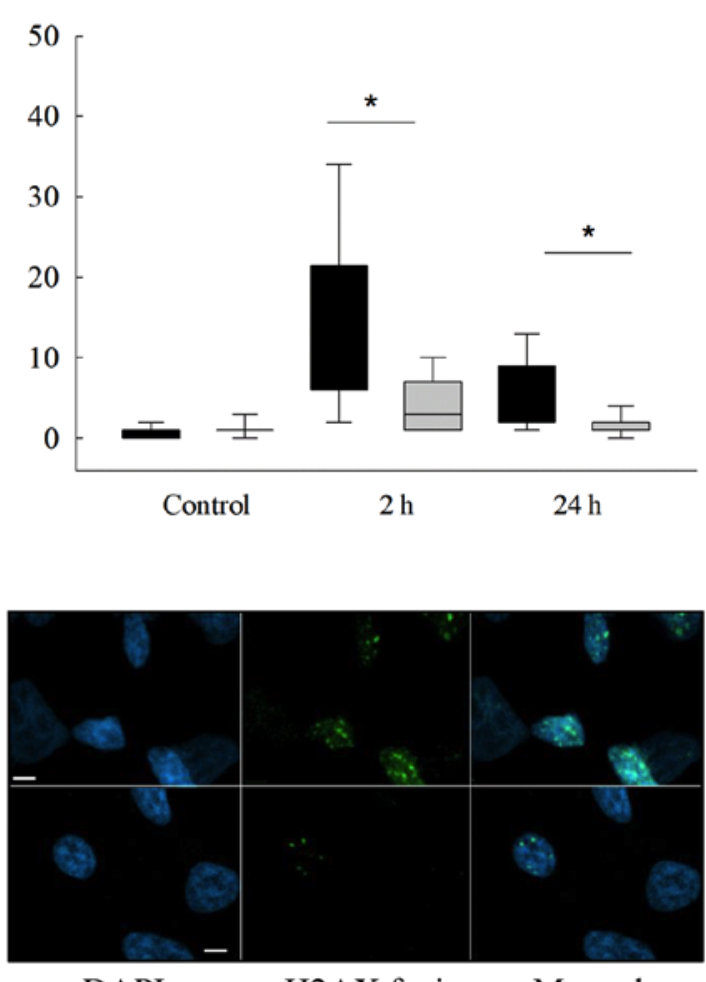

DAPI

$v \mathrm{H} 2 \mathrm{AX}$ foci

Merged

Figure 5. DNA double-strand break repair after exposure to cisplatin or bleomycin. Bar charts represent percentage of $\gamma \mathrm{H} 2 \mathrm{AX}$-positive radiosensitive (FaDu) and radioresistant (FaDu-RR) cells at different time points after exposure to cisplatin (A) or bleomycin (B). In the box plots, the number of $\gamma \mathrm{H} 2 \mathrm{AX}$ foci/nucleus at 2 time-points [18 and $48 \mathrm{~h}$ for cisplatin (C) or 2 and $24 \mathrm{~h}$ for bleomycin (D)] are shown. At each time-point at least 200 nuclei were analyzed. ${ }^{*} \mathrm{P}<0.05$ between $\mathrm{FaDu}$ and $\mathrm{FaDu}-\mathrm{RR}$ cell line. Images of $\gamma \mathrm{H} 2 \mathrm{AX}$ foci $24 \mathrm{~h}$ after exposure to chemotherapeutics were captured with a confocal microscope (Zeiss LSM 800; Carl Zeiss Microscopy GmbH, Jena, Germany), where nuclei stained with DAPI (blue) and $\gamma \mathrm{H} 2 \mathrm{AX}$ foci (green) are shown (E). Scale bar (white) represents $5 \mu \mathrm{m}$.

the most reliable in vivo assay of tumor chemosensitivity and radiosensitivity (or resistance) currently available in the clinical setting (49). The in vitro results of this study are in line with these observations. While a significant resistance of the radioresistant subline to cisplatin was observed, there was no difference between the cells in sensitivity to bleomycin. Moreover, the repair of DNA double-strand breaks after exposure to cisplatin or bleomycin was faster and more effective in the radioresistant subline, regardless of the agent they were exposed to. The explanation why the latter does not correlate with the cell survival after exposure to bleomycin may lie in different drug mechanisms of action that may be involved (50-52). We must point out that the aim of $\gamma \mathrm{H} 2 \mathrm{AX}$ immunofluorescent staining was to assess the difference between the 2 cell lines in the amount and repair-rate of DNA double-strand breaks after exposure to chemotherapeutics, used in electrochemotherapy. Since the electroporation (as a delivery system) only facilitates the passage of the drugs into the cells and does not interfere with the action of the drug on the DNA, we avoided adding the electroporation in this experiment.

When the exposure to cisplatin was combined with electrical pulses (electrochemotherapy), the difference in response between the cell lines was less obvious and not statistically 
significant. One of the possible reasons for this observation could be the facilitated passage of the drug through the cell membrane during the electroporation. Our results of the cisplatin uptake indicate that the radioresistant cells develop mechanisms to efflux cisplatin, influencing either active transport or passive diffusion $(53,54)$. The application of electrical pulses overcame this problem, as the uptake of cisplatin in radioresistant cells after electrochemotherapy is comparable to the uptake in the parental cells.

In vivo, the tumors established from the head and neck isogenic cell lines differed in histological characteristics. Radioresistant tumors were less vascularized and had lower proliferation rate, which can both adversely influence the response to salvage non-surgical therapies. Furthermore, the tumor models differed in response to electrochemotherapy. The radiosensitive tumors responded better to electrochemotherapy with cisplatin than the radioresistant ones. On the other hand, there was no difference between the tumor models in response to electrochemotherapy with bleomycin. Electrochemotherapy with bleomycin was in fact more effective than with cisplatin in both tumor models, but the difference was greater in FaDu-RR tumors, since they were more resistant to electrochemotherapy with cisplatin than FaDu tumors and equally sensitive to electrochemotherapy with bleomycin.

However, we must point out that the difference in response between the 2 tumor models was small and biologically not significant (there was no CR in radioresistant tumors and only one $\mathrm{CR}$ in radiosensitive tumors). Because the 2 tumor models did not differ substantially in tumorigenicity, indeed only a small or no difference was expected (43). The intracellular accumulation of cisplatin or bleomycin after electrochemotherapy was similar between the tumor models, indicating that the observed cisplatin-resistance of radioresistant tumors to electrochemotherapy is not due to the drug uptake, but rather relates to intrinsic mechanisms, such as more efficient DNA double-strand break repair, as indicated by faster resolution of $\gamma \mathrm{H} 2 \mathrm{AX}$ foci.

The specific histological characteristics of radioresistant tumors, such as the altered vasculature and distribution of the components of the extracellular matrix, may also contribute to the differential response to electrochemotherapy with cisplatin (55). Moreover, there are other possible mechanisms of cisplatin resistance that were not addressed in this study, such as intracellular inactivation of cisplatin by thiol-containing molecules, specific DNA-repair pathway mechanisms (especially the nucleotide excision repair and mismatch repair), altered apoptosis induction and epithelial-mesenchymal transition (EMT) of the cells after fractionated irradiation (56-58).

In this study, we focused only on the intrinsic resistance of tumor cells to electrochemotherapy. However, the differences in the response rate of pre-irradiated tumors to non-surgical treatment modalities could also be the result of changes in the tumor microenvironment after irradiation that may promote tumor invasion and spread through the effects on tumor vasculature, stroma and immune system (22). The most likely reason for the worse outcome of previously irradiated tumors treated by electrochemotherapy in patients, could be the radiotherapy-induced damaged vasculature and proliferation of fibrous tissue in the tumor bed that could compromise the chemotherapeutic delivery in sufficient concentration to the site of electroporation $(20,59)$. The data in the literature, though, do not report on the vascular lock after the delivery of electric pulses, which in the case of hampered tumor vascularization after irradiation could be less expressed.

There are limitations of the present study that should be addressed. As described above, only intrinsic radioresistance of the cells was evaluated. Due to the nature of the tumor cells, the xenografts could only be induced in immuno-compromised SCID mice; consequently, the adaptive immune system that could also play a role in response to electrochemotherapy, was excluded. Exploring the role of the immune system in the response of such tumors to electrochemotherapy would demand a different design of the study, performing other or additional experiments $(4,5,60)$. As this study deals mainly with intrinsic radioresistance of tumor cells, including these experiments would be beyond the scope of the research.

In order to fully understand the impact of previous irradiation of the tumors on the response to salvage electrochemotherapy, further studies should be employed, such as experiments on in vivo established recurrent tumors after previous (chemo)radiotherapy in immuno-competent mice where the tumor bed effect and immune response could be evaluated as well. Unfortunately, there is currently no similar murine tumor model (39).

In conclusion, our pre-clinical study of radioresistant head and neck tumor model confirms that intrinsic radioresistance of tumor cells significantly affects the outcome of treatment of such tumors to electrochemotherapy with cisplatin, but not to electrochemotherapy with bleomycin. Due to the higher complete response rate obtained after electrochemotherapy with bleomycin compared to cisplatin, the results favor bleomycin over cisplatin-based electrochemotherapy for treatment of radioresistant tumors and/or tumors that regrow after radiotherapy.

\section{Acknowledgements}

The authors would like to thank Mira Lavric (Institute of Oncology Ljubljana, Slovenia) for her help with the cell culturing, Ilija Vojvodic (Institute of Oncology Ljubljana, Slovenia) for his contribution with the irradiation of the cells, Andreja Brozic (Institute of Oncology Ljubljana, Slovenia) for her help with flow cytometric measurements, Maja Ota (Institute of Oncology Ljubljana, Slovenia) for her help with histological staining and Barbara Staresinic (Institute of Oncology Ljubljana, Slovenia) for her help with the imaging on confocal microscope.

\section{Funding}

The present study was financially supported by the Slovenian Research Agency (program nos. P3-0003 and P3-0307) and performed within the scope of LEA-EBAM (French-Slovenian European Associated Laboratory: Pulsed Electric Fields Applications in Biology and Medicine).

\section{Availability of data and materials}

The data that support the findings of this study are available from the corresponding author upon reasonable request. 


\section{Authors' contributions}

MNZ contributed to the writing of the manuscript, performed the experiments and the statistical analysis; AP and SK performed the in vivo experiments, platinum and bleomycin accumulation; AP contributed to the protocol for membrane electropermeabilization measurement with PI; VT contributed to the establishment of the radioresistant subline; VT and BG contributed to the protocol for $\gamma \mathrm{H} 2 \mathrm{AX}$ immunofluorescent staining; MS performed the histological analysis of the tumors; MC, PS and GS conceived the study and wrote the manuscript; JS and TK contributed to the analysis of platinum and bleomycin accumulation. All the authors discussed the results and contributed to the review and writing of the final manuscript. All authors read and approved the manuscript and agree to be accountable for all aspects of the research in ensuring that the accuracy or integrity of any part of the work are appropriately investigated and resolved.

\section{Ethics approval and consent to participate}

The animal experiments were approved by the Ministry of Agriculture, Forestry and Food of the Republic of Slovenia, permit no. U34401-1/2015/16, and are in compliance with the standards required by the UKCCCR guidelines.

\section{Patient consent for publication}

Not applicable.

\section{Competing interests}

The authors declare that they have no competing interests.

\section{References}

1. Yarmush ML, Golberg A, Serša G, Kotnik T and Miklavčič D: Electroporation-based technologies for medicine: Principles, applications and challenges. Annu Rev Biomed Eng 16: 295-320, 2014.

2. Mir LM, Orlowski S, Belehradek J Jr, Teissie J, Rols PM, Sersa G, Miklavcic D, Gilbert R and Heller R: Biomedical applications of electric pulses with special emphasis on antitumor electrochemotherapy. Bioelectrochem Bioenerg 38: 203-207, 1995.

3. Sersa G, Bosnjak M, Cemazar M and Heller R: Preclinical studies on electrochemotherapy. In: Handbook of Electroporation. Miklavčič D (ed). Springer International Publishing, Cham, Switzerland, pp2153-2169, 2017.

4. CalvetCY,Famin D,AndréFM and Mir LM:Electrochemotherapy with bleomycin induces hallmarks of immunogenic cell death in murine colon cancer cells. Oncoimmunology 3: e28131, 2014.

5. Di Gennaro P, Gerlini G, Urso C, Sestini S, Brandani P, Pimpinelli $\mathrm{N}$ and Borgognoni $\mathrm{L}$ : $\mathrm{CD}^{+}{ }^{+} \mathrm{FOXP}^{+}{ }^{+} \mathrm{T}$ regulatory cells decrease and $\mathrm{CD} 3^{+} \mathrm{CD} 8^{+} \mathrm{T}$ cells recruitment in TILs from melanoma metastases after electrochemotherapy. Clin Exp Metastasis 33: 787-798, 2016

6. Sersa G, Jarm T, Kotnik T, Coer A, Podkrajsek M, Sentjurc M, Miklavcic D, Kadivec M, Kranjc S, Secerov A, et al: Vascular disrupting action of electroporation and electrochemotherapy with bleomycin in murine sarcoma. Br J Cancer 98: 388-398, 2008.

7. Mali B, Jarm T, Snoj M, Sersa G and Miklavcic D: Antitumor effectiveness of electrochemotherapy: A systematic review and meta-analysis. Eur J Surg Oncol 39: 4-16, 2013.

8. Bertino G, Sersa G, De Terlizzi F, Occhini A, Plaschke CC, Groselj A, Langdon C, Grau JJ, McCaul JA, Heuveling D, et al: European research on electrochemotherapy in head and neck cancer (EURECA) project: Results of the treatment of skin cancer. Eur J Cancer 63: 41-52, 2016.
9. Plaschke CC, Bertino G, McCaul JA, Grau JJ, de Bree R, Sersa G, Occhini A, Groselj A, Langdon C, Heuveling DA, et al: European Research on Electrochemotherapy in Head and Neck Cancer (EURECA) project: Results from the treatment of mucosal cancers. Eur J Cancer 87: 172-181, 2017.

10. Spratt DE, Gordon Spratt EA, Wu S, DeRosa A, Lee NY, Lacouture ME and Barker CA: Efficacy of skin-directed therapy for cutaneous metastases from advanced cancer: A meta-analysis. J Clin Oncol 32: 3144-3155, 2014.

11. Mevio N, Bertino G, Occhini A, Scelsi D, Tagliabue M, Mura F and Benazzo M: Electrochemotherapy for the treatment of recurrent head and neck cancers: Preliminary results. Tumori 98: 308-313, 2012.

12. Groselj A, Kos B, Cemazar M, Urbancic J, Kragelj G, Bosnjak M, Veberic B, Strojan P, Miklavcic D and Sersa G: Coupling treatment planning with navigation system: A new technological approach in treatment of head and neck tumors by electrochemotherapy. Biomed Eng Online 14 (Suppl 3): S2, 2015.

13. Seccia V, Muscatello L, Dallan I, Bajraktari A, Briganti T, Ursino S, Galli L, Falcone A and Sellari-Franceschini S: Electrochemotherapy and its controversial results in patients with head and neck cancer. Anticancer Res 34: 967-972, 2014.

14. De Virgilio A, Ralli M, Longo L, Mancini P, Attanasio G, Atturo F, De Vincentiis M and Greco A: Electrochemotherapy in head and neck cancer: A review of an emerging cancer treatment (Review). Oncol Lett 16: 3415-3423, 2018.

15. Landström F, Ivarsson M, Von Sydow AK, Magnuson A, Von Beckerath $\mathrm{M}$ and Möller C: Electrochemotherapy-evidence for cell-type selectivity in vitro. Anticancer Res 35: 5813-5820, 2015.

16. Frandsen SK and Gehl J: A review on differences in effects on normal and malignant cells and tissues to electroporation-based therapies: A focus on calcium electroporation. Technol Cancer Res Treat 17: 153303381878807, 2018.

17. PlaschkeCC,Gothelf A,GehlJ and Wessel I: Electrochemotherapy of mucosal head and neck tumors: A systematic review. Acta Oncol 55: 1266-1272, 2016.

18. Mali B, Miklavcic D, Campana LG, Cemazar M, Sersa G, Snoj $\mathrm{M}$ and Jarm T: Tumor size and effectiveness of electrochemotherapy. Radiol Oncol 47: 32-41, 2013.

19. Kunte C, Letulé V, Gehl J, Dahlstroem K, Curatolo P, Rotunno P, Muir T, Occhini A, Bertino G, Powell B, et al: Electrochemotherapy in the treatment of metastatic malignant melanoma: A prospective cohort study by InspECT. Br J Dermatol 176: 1475-1485, 2017.

20. Campana LG, Mali B, Sersa G, Valpione S, Giorgi CA, Strojan P, Miklavcic D and Rossi CR: Electrochemotherapy in non-melanoma head and neck cancers: A retrospective analysis of the treated cases. Br J Oral Maxillofac Surg 52: 957-964, 2014.

21. Campana LG, Testori A, Curatolo P, Quaglino P, Mocellin S, Framarini M, Borgognoni L, Ascierto PA, Mozzillo N, Guida M, et al: Treatment efficacy with electrochemotherapy: A multi-institutional prospective observational study on 376 patients with superficial tumors. Eur J Surg Oncol 42: 1914-1923, 2016.

22. Barker HE, Paget JT, Khan AA and Harrington KJ: The tumour microenvironment after radiotherapy: Mechanisms of resistance and recurrence. Nat Rev Cancer 15: 409-425, 2015.

23. Krause M, Dubrovska A, Linge A and Baumann M: Cancer stem cells: Radioresistance, prediction of radiotherapy outcome and specific targets for combined treatments. Adv Drug Deliv Rev 109: 63-73, 2017.

24. Peitzsch C, Kurth I, Kunz-Schughart L, Baumann M and Dubrovska A: Discovery of the cancer stem cell related determinants of radioresistance. Radiother Oncol 108: 378-387, 2013.

25. Stimac M, Dolinsek T, Lampreht U, Cemazar M and Sersa G: Gene electrotransfer of plasmid with tissue specific promoter encoding shRNA against endoglin exerts antitumor efficacy against murine TS/A tumors by vascular targeted effects. PLoS One 10: e0124913, 2015.

26. Dolinsek T, Prosen L, Cemazar M, Potocnik T and Sersa G: Electrochemotherapy with bleomycin is effective in BRAF mutated melanoma cells and interacts with BRAF inhibitors. Radiol Oncol 50: 274-279, 2016.

27. Prevc A, Bedina Zavec A, Cemazar M, Kloboves-Prevodnik V, Stimac M, Todorovic V, Strojan P and Sersa G: Bystander effect induced by electroporation is possibly mediated by microvesicles and dependent on pulse amplitude, repetition frequency and cell type. J Membr Biol 249: 703-711, 2016. 
28. Sersa G, Miklavcic M, Cemazar M, Belehradek J Jr, Jarm T and Mir LM: Electrochemotherapy with CDDP on LPB sarcoma: Comparison of the anti-tumor effectiveness in immunocompetent and immunodefficient mice. Bioelectrochem Bioenerg 43: 279-283, 1997.

29. Cemazar M, Miklavcic D and Sersa G: Intrinsic sensitivity of tumor cells to bleomycin as an indicator of tumor response to electrochemotherapy. Jpn J Cancer Res 89: 328-333, 1998.

30. Begg A: Principles and practices of the tumor growth delay assay. In: Rodent Tumor Models in Experimental Cancer Therapy. Kallman RF (ed). Pergamon Press, New York, NY, pp114-121, 1987.

31. Kranjc S, Kranjc M, Scancar J, Jelenc J, Sersa G and Miklavcic D: Electrochemotherapy by pulsed electromagnetic field treatment (PEMF) in mouse melanoma B16F10 in vivo. Radiol Oncol 50: 39-48, 2016.

32. Cemazar M, Miklavcic D, Scancar J, Dolzan V, Golouh R and Sersa G: Increased platinum accumulation in SA-1 tumour cells after in vivo electrochemotherapy with cisplatin. Br J Cancer 79: 1386-1391, 1999.

33. Kranjc S, Cemazar M, Sersa G, Scancar J and Grabner S: In vitro and in vivo evaluation of electrochemotherapy with trans-platinum analogue trans- $\left[\mathrm{PtCl}_{2}(3-\mathrm{Hmpy})_{2}\right]$. Radiol Oncol 51: 295-306, 2017.

34. Martinčič A, Cemazar M, Sersa G, Kovač V, Milačič R and Ščančar J: A novel method for speciation of Pt in human serum incubated with cisplatin, oxaliplatin and carboplatin by conjoint liquid chromatography on monolithic disks with UV and ICP-MS detection. Talanta 116: 141-148, 2013.

35. Kosjek T, Krajnc A, Gornik T, Zigon D, Groselj A, Sersa G and Cemazar M: Identification and quantification of bleomycin in serum and tumor tissue by liquid chromatography coupled to high resolution mass spectrometry. Talanta 160: 164-171, 2016.

36. Schindelin J, Arganda-Carreras I, Frise E, Kaynig V, Longair M Pietzsch T, Preibisch S, Rueden C, Saalfeld S, Schmid B, et al: Fiji: An open source platform for biological image analysis. Nat Methods 9: 676-682, 2012

37. Banáth JP, Klokov D, MacPhail SH, Banuelos CA and Olive PL: Residual gammaH2AX foci as an indication of lethal DNA lesions. BMC Cancer 10: 4, 2010.

38. Landström FJ, Reizenstein J, Adamsson GB, Von Beckerath M and Möller C: Long-term follow-up in patients treated with curative electrochemotherapy for cancer in the oral cavity and oropharynx. Acta Otolaryngol 135: 1070-1078, 2015.

39. Mcdermott N, Meunier A, Lynch TH, Hollywood D and Marignol L: Isogenic radiation resistant cell lines: Development and validation strategies. Int J Radiat Biol 90: 115-126, 2014.

40. Borràs-Fresneda $M$, Barquinero JF, Gomolka M, Hornhardt $S$, Rössler U, Armengol G and Barrios L: Differences in DNA repair capacity, cell death and transcriptional response after irradiation between a radiosensitive and a radioresistant cell line. Sci Rep 6: 27043, 2016

41. Fukuda K, Sakakura C, Miyagawa K, Kuriu Y, Kin S, Nakase Y, Hagiwara A, Mitsufuji S, Okazaki Y, Hayashizaki Y, et al: Differential gene expression profiles of radioresistant oesophageal cancer cell lines established by continuous fractionated irradiation. Br J Cancer 91: 1543-1550, 2004.

42. Gomez-Casal R, Epperly MW, Wang H, Proia DA, Greenberger JS and Gomez-Casal VL: Radioresistant human lung adenocarcinoma cells that survived multiple fractions of ionizing radiation are sensitive to HSP90 inhibition. Oncotarget 6: 44306-44322, 2015.

43. Kurth I, Hein L, Mäbert K, Peitzsch C, Koi L, Cojoc M, Kunz-Schughart L, Baumann M and Dubrovska A: Cancer stem cell related markers of radioresistance in head and neck squamous cell carcinoma. Oncotarget 6: 34494-34509, 2015.

44. de Llobet LI, Baro M, Figueras A, Modolell I, Da Silva MV, Muñoz P, Navarro A, Mesia R and Balart J: Development and characterization of an isogenic cell line with a radioresistant phenotype. Clin Trans Oncol 15: 189-197, 2013.
45. Lynam-Lennon N, Reynolds JV, Pidgeon GP, Lysaght J, Marignol L and Maher SG: Alterations in DNA repair efficiency are involved in the radioresistance of esophageal adenocarcinoma. Radiat Res 174: 703-711, 2010.

46. Xie L, Song X, Yu J, Wei L, Song B, Wang X and Lv L: Fractionated irradiation induced radio-resistant esophageal cancer EC109 cells seem to be more sensitive to chemotherapeutic drugs. J Exp Clin Cancer Res 28: 68, 2009.

47. Mihatsch J, Toulany M, Bareiss PM, Grimm S, Lengerke C, Kehlbach R and Rodemann HP: Selection of radioresistant tumor cells and presence of ALDH1 activity in vitro. Radiother Oncol 99: 300-306, 2011.

48. Eichholtz-Wirth H, Reidel G and Hietel B: Radiation-induced transient cisplatin resistance in murine fibrosarcoma cells associated with elevated metallothionein content. Br J Cancer 67: 1001-1006, 1993

49. Strojan P, Haigentz M Jr, Bradford CR, Wolf GT, Hartl DM, Langendijk JA, Rinaldo A, Eisbruch A, Mendenhall WM, Forastiere AA, et al: Chemoradiotherapy vs. total laryngectomy for primary treatment of advanced laryngeal squamous cell carcinoma. Oral Oncol 49: 283-286, 2013.

50. Hecht SM: Bleomycin: New perspectives on the mechanism of action. J Nat Prod 63: 158-168, 2000.

51. Wang Q, Cui K, Espin-Garcia O, Cheng D, Qiu X, Chen Z, Moore M, Bristow RG, Xu W, Der S, et al: Resistance to bleomycin in cancer cell lines is characterized by prolonged doubling time, reduced DNA damage and evasion of G2/M arrest and apoptosis. PLoS One 8: e82363, 2013.

52. Zuckerman JE, Raffin TA, Brown JM, Newman RA, Etiz BB and Sikic BI: In vitro selection and characterization of a bleomycin-resistant subline of B16 melanoma. Cancer Res 46: 1748-1753, 1986.

53. Gately DP and Howell SB: Cellular accumulation of the anticancer agent cisplatin: A review. Br J Cancer 67: 1171-1176, 1993.

54. Kilari D, Guancial E and Kim ES: Role of copper transporters in platinum resistance. World J Clin Oncol 7: 106-113, 2016.

55. Mesojednik S, Pavlin D, Sersa G, Coer A, Kranjc S, Grosel A, Tevz G and Cemazar M: The effect of the histological properties of tumors on transfection efficiency of electrically assisted gene delivery to solid tumors in mice. Gene Ther 14: 1261-1269, 2007.

56. Fuertes MA, Alonso C and Pérez JM: Biochemical modulation of cisplatin mechanisms of action: Enhancement of antitumor activity and circumvention of drug resistance. Chem Rev 103: 645-662, 2003.

57. Shen DW, Pouliot LM, Hall MD and Gottesman MM: Cisplatin resistance: A cellular self-defense mechanism resulting from multiple epigenetic and genetic changes. Pharmacol Rev 64: 706-721, 2002.

58. Galluzzi L, Vitale I, Michels J, Brenner C, Szabadkai G, Harel-Bellan A, Castedo M and Kroemer G: Systems biology of cisplatin resistance: Past, present and future. Cell Death Dis 5: e1257, 2014.

59. Milas L, Ito H, Hunter N, Jones S and Peters LJ: Retardation of tumor growth in mice caused by radiation-induced injury of tumor bed stroma: Dependency on tumor type. Cancer Res 46: 723-727, 1986.

60. Falk H, Lambaa S, Johannesen HH, Wooler G, Venzo A and Gehl J: Electrochemotherapy and calcium electroporation inducing a systemic immune response with local and distant remission of tumors in a patient with malignant melanoma-a case report. Acta Oncol 56: 1126-1131, 2017.

This work is licensed under a Creative Commons Attribution-NonCommercial-NoDerivatives 4.0 International (CC BY-NC-ND 4.0) License. 